\title{
Improved work capacity but unchanged peak oxygen uptake during primary rehabilitation in tetraplegic patients
}

\author{
Nils Hjeltnes ${ }^{1}$ and Harriet Wallberg-Henriksson ${ }^{2}$ \\ ${ }^{1}$ Sunnaas Hospital, 1450 Nesoddtangen, Norway, and the ${ }^{2}$ Department of Clinical Physiology, Karolinska Hospital, \\ S-171 76 Stockholm, Sweden
}

Individuals with cervical spinal cord lesions are characterised by markedly decreased aerobic capacity, accompanied by increased risk of developing cardiovascular disease. The aim of this study was to evaluate the effects of a primary rehabilitation programme that included three sessions of arm cycling per week on the endurance capacity in 10 male tetraplegic subjects (injury level C6-C8; eight ASIA-A and two ASIA-B). Peak oxygen uptake (peak $\mathrm{VO}_{2}$ ) was measured three times $($ at $\mathrm{T} 1 \approx 99 \pm 10$ days after injury, $\mathrm{T} 2 \approx 2$ months after $\mathrm{T} 1$, and at $\mathrm{T} 3$ $\approx 2$ months after T2). Ten paraplegic patients admitted to the hospital for primary rehabilitation served as controls. In the tetraplegic patients, mean peak load increased $(22 \pm 2$, $32 \pm 5$, and $32 \pm 7$ watt, at T1, T2 and T3 respectively) $(P<0.01)$, while mean peak $\mathrm{VO}_{2}$ did not change during the study $\left(0.78 \pm 0.07,0.86 \pm 0.08\right.$, and $0.81 \pm 0.061 \times \mathrm{min}^{-1}$, at $\mathrm{T} 1$, T2 and $\mathrm{T} 3$, respectively) (ns). In contrast peak $\mathrm{VO}_{2}$ was significantly higher in the paraplegic control group $\left(1.37 \pm 0.08,1.64 \pm 0.10\right.$ and $1.75 \pm 0.081 \times \mathrm{min}^{-1}$, respectively) $(P<0.001)$, and increased significantly during the study period $(P<0.001)$. Mean heart rate $(\mathrm{HR})$ and mean stroke volume (SV), measured at corresponding submaximal work loads during the study did not change significantly in the tetraplegic patients. Mean systolic blood pressure (SBP), recorded immediately after peak arm exercise was low at all three tests $(93 \pm 8,89 \pm 6$ and $84 \pm 6 \mathrm{mmHg}$ ) in the tetraplegic group. However, both muscle strength and 'activities of daily life' index improved significantly during the study period. Our results suggest that functional improvement in tetraplegic patients is not necessarily followed by aerobic metabolic improvement. We conclude that more time should be spent on arm endurance training, or training methods which activate larger muscle groups and/or increases blood pressure.

Keywords: spinal cord injuries; arm exercise; cardiac output; blood pressure; muscle strength; ADL-index

\section{Introduction}

Since the beginning of the Stoke Mandeville era, physical exercise has been considered an important rehabilitation tool for spinal cord injured (SCI) subjects to improve health and prevent complications. ${ }^{1}$ Although a causal relationship between increased physical endurance capacity and improved health has not been documented in SCI subjects, arm training has been demonstrated to improve aerobic capacity, both in chronic paraplegic ${ }^{2,3}$ and tetraplegic subjects. 4 Furthermore, the aerobic capacity in wheelchair athletes is higher than the aerobic capacity in sedentary subjects with SCI. ${ }^{6,7}$ A relationship between injury level and aerobic capacity has also been demonstrated both in chronic $^{8,9}$ and recently injured $^{10}$ SCI subjects, with the lowest endurance capacity documented in those with cervical spinal cord lesions.

Correspondence: N Hjeltnes
Tetraplegic individuals have an increased risk of developing cardiovascular disease and/or non insulin dependent diabetes mellitus (NIDDM). ${ }^{1-14}$ These patients are characterised by increased body fat and reduced lean body mass, ${ }^{15}$ as well as reduced whole body glucose uptake. ${ }^{16}$ Thus increased training and physical activity in this population may have a large therapeutic potential. The inclusion of an arm ergometer training programme, as part of a comprehensive primary rehabilitation programme in recently injured tetraplegic patients, has not previously been studied. Since there is a positive correlation between peak oxygen uptake and whole body glucose uptake in healthy individuals, ${ }^{17,18}$ we speculated that endurance training in tetraplegic subjects would similarly lead to increased peak oxygen uptake, and improve whole body glucose disposal.

The aim of the present study was to investigate aerobic capacity and cardiovascular adaptations to an arm exercise programme in a group of tetraplegic subjects during primary rehabilitation after recent 
trauma. A non-invasive rebreathing method was used to measure cardiac output during submaximal exercise. ${ }^{19-21}$ To evaluate the functional abilities of the patients, muscle strength ${ }^{22}$ and evaluation of ability to perform routine daily tasks (ADL) ${ }^{23}$ (Sunnaas hospital Activities of Daily Life, ADLindex) was assessed at the beginning and end of the study.

\section{Materials and methods}

\section{Patients}

Ten male tetraplegic patients with injury levels C6 $(n=6), \quad$ C7 $\quad(n=3)$ and C8 $(n=1)$, admitted for primary rehabilitation at Sunnaas Hospital, participated in the study. The following selection criteria were utilised: (1) The patient had to be under primary rehabilitation after a recent traumatic spinal cord injury; (2) The patient had to be able to perform arm cranking; (3) The patient had to have been tested at least three times during the rehabilitation period; (4) The patient could not suffer from complicating diseases that might interfere with the physical endurance capacity.

Ten paraplegic subjects (injury level Th7 to Th10) that fulfilled the same selection criteria, served as control subjects. All patients were classified according to the American Spinal Injury Association (ASIA)classification rules, ${ }^{22}$ and found to be ASIA-A or B. The ASIA-B subjects had only very limited sensory sparing in their sacral segments. An additional group of seven able-bodied males were also tested once (at T3) and the corresponding physiological parameters compared with the SCI groups (Table 1).

All subjects were informed about the nature, purpose and possible risks of the study before giving voluntary consent to participate. The study protcol was reviewed and approved by the Regional Ethics Committee.

\section{Procedure}

Patients were exercise tested three times during their active rehabilitation period. The first test (T1) was performed as soon as the patient was able to sit in a wheelchair and carry out vigorous arm exercise (approx. 3 months after injury). The second test (T2) was carried out $6-8$ weeks later, and the third test (T3) followed a further 6-8 week period of training (shortly before discharge from the hospital). During each test, patients performed one or two graded submaximal work bouts lasting $5 \mathrm{~min}$ each, followed by a short rest period, and then a maximal work bout lasting $3 \mathrm{~min}$ or until exhaustion. The maximal load to be used at $\mathrm{T} 1$ was decided on the basis of results obtained from a pre-test carried out two days prior to $\mathrm{T} 1$, when the patient was familiarised with the intended test procedure. The maximal load at T2 and T3 were adjusted based on submaximal heart rate response during training before T2 and T3, respectively. Some tetraplegic patients were unable to perform more than one workload, which was then considered 'peak load'.

Muscle strength, and assessment of the patients ability to carry out 'activities of daily life' (ADL), was evaluated at the start and conclusion of the study as part of the Sunnaas hospital clinical evaluation routine.

\section{Physiological assessment}

Tests were performed approximately $2 \mathrm{~h}$ after breakfast with the patients seated. Subjects were not allowed to ambulate or smoke $2 \mathrm{~h}$ prior to testing. Work was performed on a load-stabilised ergometer with electrical brakes (Jaeger, Würtzburg, Germany) adapted for arm cranking. Heart rate (HR b/min) was assessed by continuously recorded ECG (Cardioline, V5-lead). Expiratory air was collected in Douglas bags during the last minute of each submaximal period and during the last $30 \mathrm{~s}$ of the maximal load. The volume of expired air was measured by wet spirometer. Samples of this air were analyzed for $\mathrm{CO}_{2}$ and $\mathrm{O}_{2}$ concentrations in rapid $\mathrm{CO}_{2}$ (infrared) and $\mathrm{O}_{2}$ (zirconium cell) analyzers (Jaeger, Würtzburg, Germany), which were calibrated daily by gas mixtures of known $\mathrm{CO}_{2}$ and $\mathrm{O}_{2}$ concentrations. The oxygen uptake $\left(\mathrm{VO}_{2} 1 / \mathrm{min}\right.$ and $\left.\mathrm{ml} / \mathrm{kg} / \mathrm{min}\right)$ was calculated on the basis of the minute ventilation and $\mathrm{O}_{2}$ concentrations in the expired air.

A non-invasive $\mathrm{CO}_{2}$-rebreathing method was used in five of the tetraplegic patients, in all the paraplegic patients and in the able bodied controls to measure cardiac output (Q 1/min), immediately following each collection of expired air during the submaximal work bouts. ${ }^{19}$ This method is routinely used in our department and has been thoroughly described previously. $^{21}$ Stroke volume (SV) and arterio-venous

Table 1 Characteristics of the participating subjects

\begin{tabular}{|c|c|c|c|c|c|c|}
\hline Groups of patients & Age (years) & Weight ( $\mathrm{kg}$ ) & Height $(\mathrm{cm})$ & $A S I A$ class $^{b}$ & Level of injury & Injury-T1 $1^{c}$ (days) \\
\hline TETRA $(n=10)$ & $25 \pm 2$ & $67 \pm 3^{\mathrm{a}}$ & $183.5 \pm 1.8$ & $7 \mathrm{~A}, 3 \mathrm{~B}$ & $\mathrm{C} 6-\mathrm{C} 8$ & $99 \pm 6$ \\
\hline PARA $(n=10)$ & $31 \pm 4$ & $69 \pm 2^{\mathrm{a}}$ & $177.0 \pm 3.0$ & $10 \mathrm{~A}$ & $\mathrm{~T} 7-\mathrm{T} 11$ & $78 \pm 5$ \\
\hline Able bodied $(n=7)$ & $32 \pm 2$ & $77 \pm 2$ & $180.0 \pm 3.0$ & & & \\
\hline
\end{tabular}

${ }^{\mathrm{a}}$ In the beginning of the study. ${ }^{\mathrm{b}}$ American Spinal Injury Association-classification. ${ }^{\mathrm{c}}$ Interval from injury to the first test. TETRA, tetraplegic patients, PARA, paraplegic patients, AB, able-bodied controls 
oxygen difference was estimated by simple calculations ( $\mathrm{SV}=\mathrm{Q} / \mathrm{HR}$, and $\mathrm{AVO}_{2} \mathrm{D}=\mathrm{VO}_{2} / \mathrm{Q}$, respectively). The rebreathing procedure was not performed during rest or maximal exercise. Blood pressure (BP) was measured immediately after each exercise bout, using an automatically inflatable cuff around the upper arm. $^{24}$

Venous blood was drawn without stasis, from an antecubital vein 3 min after maximal exercise. Blood samples were immediately precipitated with perchloric acid and analyzed for lactic acid (LA) with an enzymatic method. ${ }^{25}$

Muscle strength was tested by a physiotherapist on a scale from $0-5$, in five upper extremity key muscles. ${ }^{22}$ Ability to carry out routine daily tasks was tested by occupational therapists according to the Sunnaas ADL index. ${ }^{23}$ Both the muscle strength and the ADL-score were measured a few weeks before starting aerobic training and immediately prior to discharge.

\section{Training}

Before starting the training programme, treatment of patients was initialised by passive joint movements, guided active limb movements, orthostatic training, breathing against resistance, and the patient mobilised to and balanced in sitting position. These sessions were continued throughout the study. However, as the study progressed, high intensity aerobic arm exercise performed for $30 \mathrm{~min}$ or until exhaustion, three times a week, was integrated into the rehabilitation programme. During these sessions, the patients worked on an arm ergometer or drove their wheelchairs outdoors. Every 3 weeks, the intensity of the training was adjusted in accordance with the results of submaximal heart rating. During the final 6-8 weeks (between T2 and T3) the aerobic training schedule was less strictly adhered to, since during this period greater emphasis was placed on training in routine daily tasks, driving skills and preparing patients for discharge and subsequent return home.

\footnotetext{
Statistics

Data are presented as mean \pm SEM. Analysis of variance (ANOVA-Repeated Measures) was used to analyse the differences between the tests (points of time or training effect $=$ within group variations), and ANOVA-Repeated Measures with two groups (one factor), was used to analyze both variation within groups (time*groups) and variation between groups during exercise. A contrast matrix was specified to cover the significance of the difference between the adjacent tests. Students $t$-test for two samples (separate variances) was used with Bonferoni's corrections to analyze differences between the Para and the AB group at T3. Students $t$-test for paired observations was used to compare muscle strength values and ADL-score before and after the training.
}

\section{Results}

The special arm exercise testing and training sessions commenced following the early rehabilitation phase, when the patients were allowed to perform vigorous arm exercise $(99 \pm 6$ days and $78 \pm 5$ days after injury for the tetraplegic and paraplegic group, respectively) (Table 1). Mean body weight during the study period did not change significantly for the tetraplegic group $(67.3 \pm 2.7,68.0 \pm 2.7$, and $67.1 \pm 2.6 \mathrm{~kg}$ at $\mathrm{T} 1,2$ and 3 , respectively (ns), or for the paraplegic group $(69 \pm 2$, $66 \pm 1$ and $68 \pm 2 \mathrm{~kg}$., ns).

\section{Maximal exercise}

Peak load (watt) increased, while $\mathrm{VO}_{2}$, heart rate, systolic blood pressure, and lactate levels were unaltered in the Tetraplegic group during the course of the present study (Table 2). In contrast a $28 \%$ increase in peak oxygen uptake was observed in the Para group (Table 2). At the end of the study, mean peak oxygen uptake in the paraplegic group remained $38 \%$ lower than the mean peak $\mathrm{VO}_{2}$ in the able bodied group (Table 2).

Significantly lower ventilation during peak exercise was observed in the tetraplegic group $(35 \pm 4,33 \pm 5$, and $32 \pm 41 / \mathrm{min}$ at $\mathrm{T} 1,2$ and 3 , respectively), compared to the paraplegic group $(60 \pm 4,68 \pm 3$, and $67 \pm 41 / \mathrm{min}) \quad(P<0.001)$, and this could be accounted for by a lower tidal volume during exercise in the tetraplegic group $(P<0.001)$ (Figure 1). A low mean peak heart rate was observed at all three tests in the tetraplegic group compared to the paraplegic group $(P<0.001)$, while no difference was observed between the paraplegic and the able-bodied group (Table 2). Systolic blood pressure, measured immediately after the peak exercise load, did not change during the study period in any of the groups. However, the mean blood pressure in the tetraplegic group was significantly lower at all three tests compared to the paraplegic group $(P<0.01)$ (Table 2). The mean peak pulse-rate-product $(\mathrm{PRP}=\mathrm{HR} * \mathrm{SBP})$ was not changed during the study period in any of the groups (Figure 2). However, the PRP was markedly lower in the Tetraplegic group compared to the paraplegic group $(P<0.001)$ (Figure 2).

Mean lactate values, assessed 3 min following peak exertion, did not change during the study period, but were lower in the tetraplegic compared to the paraplegic group (Table 2). The RQ values during peak load in the tetraplegic group $(1.00 \pm 0.05$, $0.93 \pm 0.03$ and $0.91 \pm 0.03$ at $\mathrm{T} 1,2$ and 3 , respectively) were significantly lower than that observed in the paraplegic group $(1.09 \pm 0.05,1.12 \pm 0.03$ and $1.07 \pm 0.03) ;(P<0.01)$.

\section{Submaximal exercise}

Only five of the tetraplegic patients were able to perform a submaximal bout of exercise before the 
Table 2 Measured parameters during peak arm ergometry in 10 tetraplegic patients, 10 paraplegic patients, and seven able bodied controls. The tetraplegic and the paraplegic groups were tested at three points of time during the primary rehabilitation period (Test 1, Test 2 and Test 3, respectively). The able-bodied subjects were only tested at one time (Test 3). TETRA, tetraplegic patients, PARA, paraplegic patients, AB, able-bodied controls

\begin{tabular}{|c|c|c|c|c|c|c|}
\hline \multicolumn{2}{|c|}{ Peak effort } & $\begin{array}{c}\text { Test } 1 \\
(\approx 3 \text { months } \\
\text { after injury })\end{array}$ & $\begin{array}{c}\text { Test } 2 \\
(\approx 5 \text { months } \\
\text { after injury })\end{array}$ & $\begin{array}{c}\text { Test } 3 \\
(\approx 7 \text { months } \\
\text { after injury) }\end{array}$ & $\begin{array}{c}\text { P-values for } \\
\text { training effects }^{a}\end{array}$ & $\begin{array}{l}P \text {-values versus } \\
\text { other groups }\end{array}$ \\
\hline $\begin{array}{l}\text { Load } \\
\text { (watt) }\end{array}$ & $\begin{array}{l}\text { TETRA } \\
\text { PARA } \\
\text { AB }\end{array}$ & $\begin{array}{l}22 \pm 2^{*} \\
75 \pm 6^{*}\end{array}$ & $\begin{array}{l}32 \pm 5 \\
97 \pm 6\end{array}$ & $\begin{array}{l}32 \pm 7 \\
107 \pm 5 \\
167 \pm 11\end{array}$ & $\begin{array}{l}P<0.01 \\
P<0.001\end{array}$ & $\begin{array}{l}P<0.001^{\mathrm{b}} \\
P<0.05^{\mathrm{c}}\end{array}$ \\
\hline $\begin{array}{l}\mathrm{VO}_{2} \\
(1 / \mathrm{min})\end{array}$ & $\begin{array}{l}\text { TETRA } \\
\text { PARA } \\
\text { AB }\end{array}$ & $\begin{array}{l}0.78 \pm 0.07 \\
1.37 \pm 0.08 *\end{array}$ & $\begin{array}{l}0.86 \pm 0.08 \\
1.64 \pm 0.10\end{array}$ & $\begin{array}{l}0.81 \pm 0.06 \\
1.75 \pm 0.08 \\
2.82 \pm 0.15\end{array}$ & $\begin{array}{c}\text { ns } \\
P<0.001\end{array}$ & $\begin{array}{l}P<0.001^{\mathrm{b}} \\
P<0.001^{\mathrm{c}}\end{array}$ \\
\hline $\begin{array}{l}\mathrm{HR} \\
(\mathrm{b} / \mathrm{min})\end{array}$ & $\begin{array}{l}\text { TETRA } \\
\text { PARA } \\
\text { AB }\end{array}$ & $\begin{array}{l}110 \pm 5 \\
182 \pm 3\end{array}$ & $\begin{array}{l}125 \pm 6 \\
179 \pm 3\end{array}$ & $\begin{array}{l}119 \pm 3 \\
181 \pm 3 \\
173 \pm 2\end{array}$ & $\begin{array}{l}\mathrm{ns} \\
\mathrm{ns}\end{array}$ & $\begin{array}{c}P<0.001^{\mathrm{b}} \\
\mathrm{ns}\end{array}$ \\
\hline $\begin{array}{l}\text { SBP } \\
(\mathrm{mmHg})\end{array}$ & $\begin{array}{l}\text { TETRA } \\
\text { PARA } \\
\text { AB }\end{array}$ & $\begin{array}{c}93 \pm 8 \\
161 \pm 10\end{array}$ & $\begin{array}{r}89 \pm 6 \\
167 \pm 7\end{array}$ & $\begin{array}{r}84 \pm 6 \\
146 \pm 8 \\
163 \pm 5\end{array}$ & $\begin{array}{l}\text { ns } \\
\text { ns }\end{array}$ & $\begin{array}{c}P<0.01^{\mathrm{b}} \\
\mathrm{ns}\end{array}$ \\
\hline $\begin{array}{l}\mathrm{LA} \\
(\mathrm{mM})\end{array}$ & $\begin{array}{l}\text { TETRA }(\mathrm{n}=4) \\
\text { PARA }(\mathrm{n}=6) \\
\text { AB }\end{array}$ & $\begin{array}{r}5.86 \pm 1.32 \\
12.34 \pm 0.94\end{array}$ & $\begin{array}{r}4.69 \pm 1.26 \\
10.53 \pm 0.78\end{array}$ & $\begin{array}{r}5.77 \pm 1.16 \\
10.82 \pm 0.96 \\
12.20 \pm 0.75\end{array}$ & $\begin{array}{l}\mathrm{ns} \\
\mathrm{ns}\end{array}$ & $\begin{array}{c}P<0.01^{\mathrm{b}} \\
\mathrm{ns}\end{array}$ \\
\hline
\end{tabular}

${ }^{a}$ One-way ANOVA repeated measurements was used to test the training effects in each group. ${ }^{b}$ ANOVA-repeated measurements with one within factor was used to test the differences between the TETRA and the PARA groups. ${ }^{\mathrm{c}}$ Two sample $t$-test was used to analyze the differences at test three between the PARA and the AB groups. *Indicates that the value is significantly different from the next adjacent value (ANOVA-Contrast-Difference)

maximal load at all three tests. Exercise was performed at lower absolute submaximal load in the tetraplegic group than in the paraplegic group at all three tests $(P<0.001)$, and taxed a greater percent of peak aerobic capacity (Table 3 ). In the tetraplegic group, the oxygen uptake at the same submaximal work load increased from T1-T3 $(P<0.05)$ (Table 3$)$. Mean submaximal HR was significantly lower in the tetraplegic group than in the paraplegic group $(P<0.01)$ at all three tests, even though the tetraplegic patients were exercising on a much higher per cent of peak aerobic capacity. The paraplegic group demonstrated a reduction in $\mathrm{HR}$ at the submaximal workload during T2 and 3 compared to T1 $(P<0.01)$ (Table 3). Neither cardiac output, stroke volume (Table 3), nor calculated arterio-venous oxygen difference $(11.2 \pm 0.6,11.5 \pm 0.7,11.8 \pm 1.3$ at $\mathrm{T} 1,2$, and 3 in the tetraplegic group, and $12.6 \pm 0.5$, $13.2 \pm 0.4$, and $12.8 \pm 0.3$ in the paraplegic group), changed at corresponding submaximal work loads in any group during the study.

A submaximal workload of 30 watt required a significantly smaller fraction of peak $\mathrm{VO}_{2}$ in the ablebodied group than in the paraplegic group (Table 3 ). Heart rate was significantly lower, and stroke volume was significantly higher in the able-bodied individuals than corresponding submaximal values in the paraplegic group (Table 3). Mean submaximal oxygen uptake and cardiac output, were the same in the

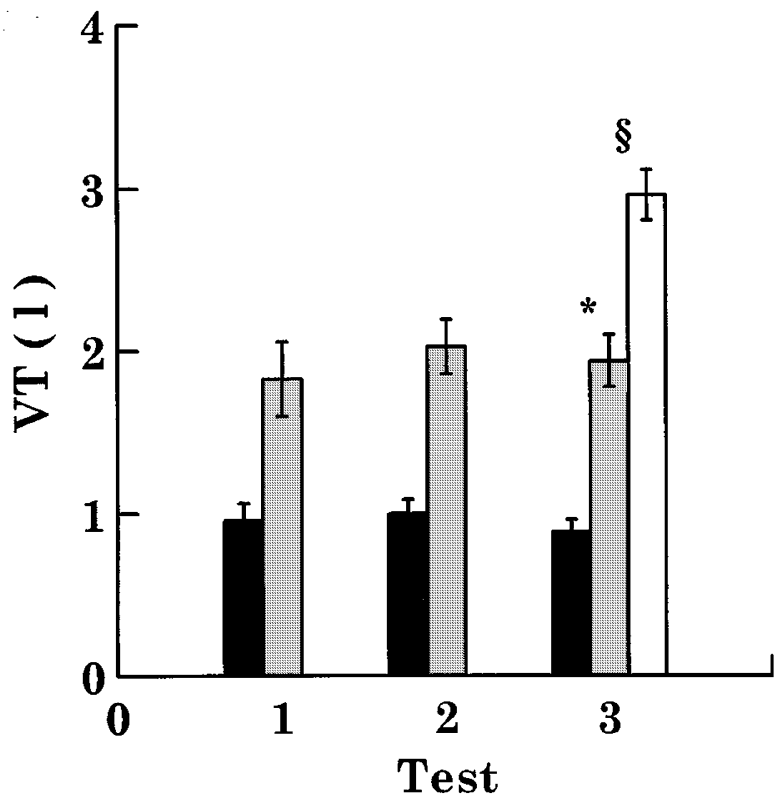

Figure 1 Mean tidal volume (TV) during peak arm exercise at T1, T2 and T3 in the tetraplegic (dense bars), and the paraplegic (hatched bars) groups. Able-bodied controls were only tested at T3 (open bars). TV was significantly lower $(P<0.001$, ANOVA-repeated measurements $)$ in the tetraplegic than in the paraplegic group $(*)$, and lower in the paraplegic group compared to the Able-bodied group (§) at T3 $(P<0.001$, student-test two groups) 


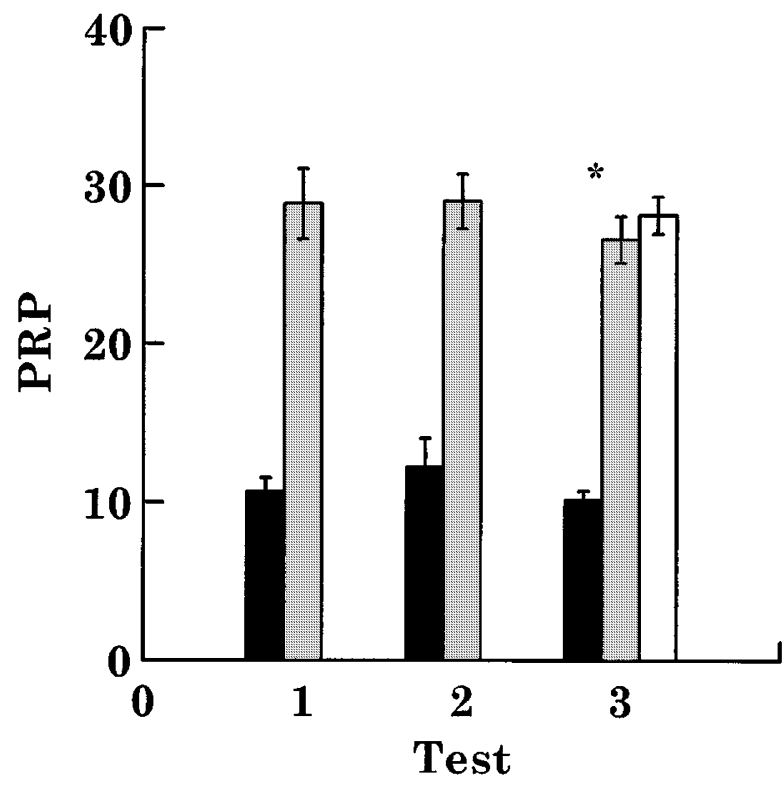

Figure 2 Mean pulse product $(\mathrm{PP}=\mathrm{HR} * \mathrm{SBP})$ during peak arm exercise at T1, T2 and T3 in the tetra- (dense bars), paraplegic- (hatched bars) and the able-bodied control group (tested only at T3). While a highly significant difference was observed between the tetraplegic and the paraplegic group $*^{*}$ $(P<0.001)$, no difference was observed between the paraplegic and the able-bodied groups paraplegic and the able-bodied groups at corresponding absolute workloads.

Muscle strength and $A D L$-index

Mean muscle strength in the five tested upper extremity muscles increased by more than six points $(P<0.001)$ in the tetraplegic patients. A corresponding significant increase was noted in ADL score $(P<0.001)$ from before to after the study period (Table 4$)$.

\section{Discussion}

The present study demonstrates that scheduled aerobic arm exercise three times a week during primary rehabilitation, contribute to increase muscle strength, ADL performance and the ability to sustain heavy arm load during arm cycling in tetraplegic patients. However, despite this, no improvement in peak oxygen uptake was observed in the tetraplegic subjects during the primary rehabilitation period $3-7$ months following the injury. Between 3 and 5 months following injury there was a tendency towards increased peak $\mathrm{VO}_{2}$ ( $\mathrm{T} 1$ to $\mathrm{T} 2$ ), however, this was reversed from the fifth to the seventh month (T2 to T3). In contrast, a highly significant increase in peak oxygen uptake was

Table 3 Measured parameters during submaximal arm ergometry in five tetraplegic patients, 10 paraplegic patients, and seven able-bodied controls. The tetraplegic and the paraplegic groups were tested at three points of time during the primary rehabilitation period (Test 1, Test 2 and Test 3, respectively). The AB subjects were only tested at one time (T3). TETRA, tetraplegic patients, PARA, paraplegic patients, AB, able-bodied controls

\begin{tabular}{|c|c|c|c|c|c|c|}
\hline \multicolumn{2}{|c|}{ Measured parameters } & $\begin{array}{c}\text { Test } 1 \\
(\approx 3 \text { months } \\
\text { after injury })\end{array}$ & $\begin{array}{c}\text { Test } 2 \\
(\approx 5 \text { months } \\
\text { after injury })\end{array}$ & $\begin{array}{c}\text { Test } 3 \\
(\approx 7 \text { months } \\
\text { after injury) }\end{array}$ & $\begin{array}{c}P \text {-values for } \\
\text { training effects }^{a}\end{array}$ & $\begin{array}{c}P \text {-values versus } \\
\text { PARA } \text { group }^{b}\end{array}$ \\
\hline $\begin{array}{l}\text { Load } \\
\text { (watt) }\end{array}$ & $\begin{array}{l}\text { TETRA } \\
\text { PARA } \\
\text { AB }\end{array}$ & $\begin{array}{l}10 \\
30\end{array}$ & $\begin{array}{l}10 \\
30\end{array}$ & $\begin{array}{l}10 \\
30 \\
30\end{array}$ & $\begin{array}{l}\text { ns } \\
\text { ns }\end{array}$ & $\begin{array}{c}P<0.001 \\
\text { ns }\end{array}$ \\
\hline $\begin{array}{l}\mathrm{VO}_{2} \\
(1 / \mathrm{min})\end{array}$ & $\begin{array}{l}\text { TETRA } \\
\text { PARA } \\
\text { AB }\end{array}$ & $\begin{array}{l}0.60 \pm 0.07 \\
0.91 \pm 0.05\end{array}$ & $\begin{array}{l}0.67 \pm 0.04 \\
0.88 \pm 0.03\end{array}$ & $\begin{array}{l}0.75 \pm 0.06 \\
0.86 \pm 0.04 \\
0.90 \pm 0.06\end{array}$ & $P<0.05$ & $\begin{array}{c}P<0.01 \\
\text { ns }\end{array}$ \\
\hline $\begin{array}{l}\% \text { Peak } \mathrm{VO}_{2} \\
(\%)\end{array}$ & $\begin{array}{l}\text { TETRA } \\
\text { PARA } \\
\text { AB }\end{array}$ & $\begin{array}{l}78 \pm 4 \\
68 \pm 5\end{array}$ & $\begin{array}{l}76 \pm 7 \\
55 \pm 3\end{array}$ & $\begin{array}{l}81 \pm 7 \\
50 \pm 3 \\
32 \pm 2\end{array}$ & $\begin{array}{c}\text { ns } \\
P<0.01\end{array}$ & $\begin{array}{r}P<0.001 \\
P<0.001\end{array}$ \\
\hline $\begin{array}{l}\mathrm{HR} \\
(\mathrm{b} / \mathrm{min})\end{array}$ & $\begin{array}{l}\text { TETRA } \\
\text { PARA } \\
\text { AB }\end{array}$ & $\begin{array}{l}109 \pm 2 \\
141 \pm 6\end{array}$ & $\begin{array}{l}110 \pm 7 \\
121 \pm 4\end{array}$ & $\begin{array}{r}101 \pm 5 \\
121 \pm 5 \\
93 \pm 5\end{array}$ & $\begin{array}{c}\text { ns } \\
P<0.01\end{array}$ & $\begin{array}{l}P<0.01 \\
P<0.01\end{array}$ \\
\hline $\begin{array}{l}\mathrm{Q} \\
(1 / \min )\end{array}$ & $\begin{array}{l}\text { TETRA } \\
\text { PARA } \\
\text { AB }\end{array}$ & $\begin{array}{l}5.5 \pm 0.6 \\
7.3 \pm 0.4\end{array}$ & $\begin{array}{l}6.0 \pm 0.7 \\
6.7 \pm 0.3\end{array}$ & $\begin{array}{l}6.8 \pm 1.2 \\
6.7 \pm 0.3 \\
7.8 \pm 0.8\end{array}$ & $\begin{array}{l}\text { ns } \\
\text { ns }\end{array}$ & $\begin{array}{l}\text { ns } \\
\text { ns }\end{array}$ \\
\hline $\begin{array}{l}\text { SV } \\
(\mathrm{ml})\end{array}$ & $\begin{array}{l}\text { TETRA } \\
\text { PARA } \\
\text { AB }\end{array}$ & $\begin{array}{l}50 \pm 4 \\
52 \pm 4\end{array}$ & $\begin{array}{l}55 \pm 5 \\
55 \pm 2\end{array}$ & $\begin{array}{l}69 \pm 14 \\
56 \pm 2 \\
85 \pm 8\end{array}$ & $\begin{array}{l}\text { ns } \\
\text { ns }\end{array}$ & $\begin{array}{c}\mathrm{ns} \\
P<0.01\end{array}$ \\
\hline
\end{tabular}

${ }^{\mathrm{a} O n e-w a y ~ A N O V A ~ r e p e a t e d ~ m e a s u r e m e n t s ~ w a s ~ u s e d ~ t o ~ t e s t ~ t h e ~ t r a i n i n g ~ e f f e c t s ~ i n ~ e a c h ~ g r o u p . ~}{ }^{\mathrm{b}}$ ANOVA-repeated measurements with one within factor was used to test the differences between the TETRA and the PARA groups 
Table 4 Mean motor score according to standard neurological classification in spinal cord injury, and mean Sunnaas ADL-index score in the tetraplegic group, before and after the training period

\begin{tabular}{lrcc}
\hline Test & $\begin{array}{c}\text { Before } \\
\text { training }\end{array}$ & $\begin{array}{c}\text { After } \\
\text { training }\end{array}$ & $\begin{array}{c}\text { for training } \\
\text { effects }^{a}\end{array}$ \\
\hline Muscle strength score & $18.9 \pm 1.7$ & $25.0 \pm 2.0$ & $P<0.001$ \\
ADL-score & $7.5 \pm 0.5$ & $18.8 \pm 0.8$ & $P<0.001$ \\
\hline
\end{tabular}

${ }^{\mathrm{a} S t u d e n t s} t$-test for paired observations

observed in the paraplegic subjects. Cardiovascular disease and NIDDM occurs relatively more frequently, and at an earlier age in SCI subjects as compared to able-bodied individuals. ${ }^{26}$ Furthermore, in able-bodied people there is a positive relationship between physical endurance capacity, lean body mass and improved insulin sensitivity. ${ }^{17,18}$ However, the results of this study indicate that arm exercise may not counteract the increased risk of developing these complications in the tetraplegic patients. Mean submaximal heart rate and stroke volume did not change during the study period. Thus, the present rehabilitation programme including sessions with arm ergometry, did not lead to improved cardiovascular functions in the tetraplegic subjects between the 3rd and the 7th month of the primary rehabilitation period. The finding of altered oxygen uptake at identical submaximal workloads in the tetraplegic group indicates that factors other than the workload influence oxygen consumption. Such factors are probably related to an unstable physiological situation (altered body mass, altered muscular tone, altered autonomic spinal reflexes, and altered pulmonary function) during the study period.

The peak oxygen uptake of the tetraplegic subjects in this study is in accordance with, or higher than, peak $\mathrm{VO}_{2}$ reported in untrained tetraplegic subjects in other studies, ${ }^{4,7,10,27-29}$ but are lower than those observed in trained tetraplegic subjects. ${ }^{4-9}$ The lack of increase in peak $\mathrm{VO}_{2}$ in our study is in contrast with the results in a recently published study of chronic tetraplegic subjects. ${ }^{5}$ However, in the latter study, the time to exhaustion increased more than the peak $\mathrm{VO}_{2}$. In another study, peak $\mathrm{VO}_{2}$ increased following 7 weeks of wheelchair training on a motor driven treadmill. However, three out of nine subjects in that study had high level paraplegic lesions, and trained five times per week. ${ }^{4}$

An ability to sustain a higher peak load without a corresponding increase in peak $\mathrm{VO}_{2}$, as noted in the present study, suggests improved exercise technique, or altered intracellular metabolism. During aerobic training the muscle gradually changes from carbohydrate to fat combustion, and this may also occur in muscle of SCI subjects. ${ }^{30}$ However, the low peak $\mathrm{VO}_{2}$ in the tetraplegic patients is also in contrast to the relatively high endurance capacity that has been achieved in tetraplegic wheelchair athletes. ${ }^{7,31-33}$

From a physiological point of view, it seems logical that cardiac function will deteriorate in tetraplegic subjects due to the limited amount of muscles available to perform exercise. Such deterioration has been demonstrated in the form of marked myocardial hypotrophy in chronic tetraplegic subjects. ${ }^{34,35}$ The low stroke volumes observed in the tetraplegic subjects, measured in the sitting position, are consistent with earlier reports using non invasive methods to measure cardiac output. ${ }^{21,26,36}$ Furthermore we report that stroke volume during submaximal exercise is unaltered, suggesting that ionotrophic training effects do not occur in the heart muscle. ${ }^{33}$ In the present study the recommended Collier's method was used to determine venous tension of $\mathrm{CO}_{2}$ $\left(\mathrm{P}_{\mathrm{v}} \mathrm{CO}_{2}\right){ }^{37}$ End tidal tension of $\mathrm{CO}_{2}\left(\mathrm{P}_{\mathrm{ET}} \mathrm{CO}_{2}\right)$ was used to estimate arterial $\mathrm{CO}_{2}$ tension $\left(\mathrm{P}_{\mathrm{A}} \mathrm{CO}_{2}\right)$, and Godfrey's recommendations were used to estimate $\mathrm{CO}_{2}$ content. ${ }^{38}$ This combination has been found to give highly reproducible results (coefficient of variation $5.7 \%$ ) during submaximal exercise in healthy individuals. $^{20}$ The results are also in agreement with the results obtained by the direct Fick method ${ }^{39}$ and the dye dilution method. ${ }^{40}$ However, since only limited data is available for establishing the validity of indirect methods in able-bodied individuals, and no data is available in tetraplegic subjects, it is important to be aware of the assumptions and potential errors that may occur when using these techniques. ${ }^{41}$

Low blood pressure, recorded immediately after bouts of exercise in the tetraplegic subjects, ${ }^{42}$ contributes to a low pulse rate product, which further indicates that the myocardial capacity is not the limiting factor for exercise. During the present study the tetraplegic subjects reported stiff upper arm muscles as the main cause of exhaustion. Even though minute ventilation during peak exercise usually requires less than $50 \%$ of their maximal ventilatory capacity, ${ }^{10}$ diaphragmatic fatigue might have contributed to the exhaustion in some tetraplegic subjects. ${ }^{43}$

The endurance capacity of the paraplegic group at the end of the study period (T3), was significantly lower than the aerobic capacity of the able bodied group in the present study, as well as the reported levels in paraplegic wheelchair athletes. ${ }^{8}$ Thus, our results for the paraplegic patients suggest that increased physical endurance training during primary rehabilitation may lead to higher endurance capacity.

It is important to note that in both groups of patients in the present study, patients were also involved in programmes aimed at improving function during routine daily tasks and social activities in order to prepare for an independent living outside the institution. These activities were especially emphasised during the period between T2 and T3. However, clinical routine evaluation demonstrated significantly improved muscle strength and ADL-score in the tetraplegic subjects at the end of the study period as 
compared to before. Therefore arm ergometer training might be considered time consuming, or unimportant to include in conjunction with the other routine daily tasks. Furthermore, high intensity arm ergometry may lead to overuse injuries in the shoulders or elbows.

The presented results raises the question if improved muscle strength, improved ADL-score and ability to tolerate higher arm cycle loads, indicates that the rehabilitation training programme is sufficient and/or desirable, as long as peak $\mathrm{VO}_{2}$, the parameter that is most closely related to whole body glucose uptake, is unchanged in the tetraplegic group. Instead, more specialised training and care should probably be focused on a custom rehabilitation programme aimed at improving endurance capacity in tetraplegic subjects. Otherwise a vicious cycle of low aerobic capacity leading to even more physical inactivity, might accelerate long term physical deterioration. For tetraplegic subjects, the training must take into account the limited amount of voluntarily controlled muscle mass and the comprised sympathetic system.

In conclusion, the results of the present study indicate that primary rehabilitation programmes are likely to contain insufficient endurance training for tetraplegic subjects to secure long term improvement in their endurance capacity. Although functional improvements are demonstrated during primary rehabilitation, addition of supplementary training methods may be beneficial in order to activate larger muscle groups.

\section{Acknowledgements}

We are grateful to Juleen Zierath and Prof John Wahren for their criticism and careful reading of the manuscript.

\section{References}

1 Guttmann L. New hope for spinal cord sufferers. $N Y$ Med Times 1945; 73: $318-327$.

2 Knutsson E, Lewenhaupt-Olsson E, Thorsen M. Physical work capacity and physical conditioning in paraplegic patients. Paraplegia 1973 ; 11: 205-216.

3 Nilsson S, Staff PH, Pruett E DR. Physical work capacity and the effect of training on subjects with long-standing paraplegia. Scand J Rehab Med 1975; 7: 51-56.

4 Gass GC et al. The effects of physical training on high level spinal lesion patients. Scand J Rehab Med 1980; 12: 61-65.

5 McLean KP, Skinner JS. Effect of body training position on outcomes of an aerobic training study on individuals with quadraplegia. Arch Phys Med Rehabil 1995; 76: 139-150.

6 Zwiren LD, Bar-Or O. Response to exercise of paraplegics who differ in conditioning level. Med Sci in Sports Exerc 1975; 7: $94-$ 97.

7 Eriksson P, Løfstrøm L, Ekblom B. Aerobic power during maximal exercise in untrained and well-trained persons with quadraplegia and paraplegia. Scand J Rehab Med 1988; 20: 141 147.

8 Wicks JR, Oldridge NB, Cameron BJ, Jones NL. Arm cranking and wheelchair ergometry in elite spinal cord-injured athletes. Med Sci Sports Exerc 1983; 15: 224-231.
9 Coutts KD, Rhodes EC, McKenzie DC. Maximal exercise responses of tetraplegics and paraplegics. $J$ Appl Physiol: Respirat Environ Exercise Physiol 1983; 55: 479-482.

10 Hjeltnes N. Cardiorespiratory capacity in tetra- and paraplegia shortly after injury. Scand J Rehab Med 1986; 18: 65-70.

11 Yekutiel $\mathrm{M}$ et al. The prevalence of hypertension, ischemic heart disease and diabetes in traumatic spinal cord injured patients and amputees. Paraplegia 1989; 27: $28-62$.

12 Krum $\mathrm{H}$ et al. Risk factors for cardiovascular disease in chronic spinal cord injury patients. Paraplegia 1992; 30: $381-388$.

13 Whiteneck GG et al. Mortality, morbidity, and psychosocial outcomes of persons spinal cord injured more than 20 years ago. Paraplegia 1992; 30: 617-630.

14 Bauman WA, Spungen AM. Disorders of carbohydrate and lipid metabolism in veterans with paraplegia or quadraplegia: a model of premature aging. Metabolism 1994; 43: 749-756.

15 Spungen AM, Bauman WA, Wang J, Pierson Jr, RN Measurement of body fat in individuals with tetraplegia: a comparison of eight clinical methods. Paraplegia 1995; 33: 402 408.

16 Aksnes AK et al. Intact glucose transport system in centrally denervated, morphologically altered skeletal muscle from tetraplegic patients. Am J Physiol (Endocrinol Metab) 1996; 271: E593-E600.

17 Yki-Järvinen H, Koivisto VA. Effects of body composition on insulin sensitivity. Diabetes 1983; 32: 965-969.

18 Rodnick KJ et al. Improved insulin action in muscle, liver and adipose tissue in physically trained humans. Am J Physiol (Endocrinol Metab) 1987; 253; E489 - E495.

19 Godfrey S. Measurement of cardiac output in children by the indirect (CO2) Fick method In: Exercise testing in children. Saunders: London, Philadelphia and Toronto, 1974, pp 42-65.

20 Zeidifard E, Silverman M, Godfrey S. Reproducibility of indirect (CO2) Fick method for calculation of cardiac output. J Apply Physiol 1972; 33: $141-143$.

21 Hjeltnes N. Oxygen uptake and cardiac output in graded arm exercise in paraplegics with low level spinal lesions. Scand J Rehab Med 1977; 9: 107 - 113 .

22 Ditunno JF. The international standards booklet of neurological and functional classification of spinal cord injury. Paraplegia 1994; 32: $70-80$.

23 Vardeberg K, Kolsrud M, Laberg T. Sunnaas Index of ADL. WFOT Bulletin 1991; 34: 30-35.

24 Hoobler SW, Oesterle B, Early H. Evaluation of a new automatic device for taking and recording blood pressures. J Lab Clin Med (St Louis) 1976; 88: 826-833.

25 Olsen C. An enzymatic fluorimetric micromethod for the determination of acetoacetate, beta-hydroxybutyrate, pyruvate and lactate. Clin Chim Acta 1971; 33: 293-300.

26 Bauman WA et al. Coronary artery disease: Metabolic risk factors and latent disease in individuals with paraplegia. Mount Sinai Journal of Medicine 1992; 59: 163-168.

27 Van Loan MD, McCluer S, Loftin JM, Boileau RA. Comparison of physiological responses to maximal arm exercise among ablebodied, paraplegics and quadraplegics. Paraplegia 1987; 25: $397-405$.

28 Burkett LN, Chisum J, Stone W, Fernhall B. Exercise capacity of untrained spinal cord injured individuals and the relationship of peak oxygen uptake to level of injury. Paraplegia 1990; 28: 512 521.

29 Dallmeijer AJ, Hopman M-TE, van As HHJ, van der Woude LHV. Physical capacity and physical strain in persons with tetraplegia; The role of sport activity. Spinal Cord 1996; 34: $729-$ 735 .

30 Flandrois $\mathrm{R}$ et al. Aerobic performance capacity in paraplegic subjects. Eur J Appl Physiol 1986; 55: 604-609.

31 Okuma H, Ogata H, Hatada K. Transition of physical fitness in wheelchair marathon competitors over several years. Paraplegia 1989; 27: $237-243$.

32 Hooker SP, Wells CL. Aerobic power of competitive road racers. Paraplegia 1992; 30: 428 - 436. 
33 Bhambhani YN, Holland LJ, Eriksson P, Steadward RD Physiological responses during wheelchair racing in quadraplegics and paraplegics. Paraplegia 1994; 32: 253-260.

34 Kessler KM et al. Cardiovascular findings in quadraplegic and paraplegic patients and in normal subjects. Am J Cardiol 1986; 58: $525-530$.

35 Nash MS et al. Reversal of adaptive left ventricular atrophy following electrically-stimulated exercise training in human tetraplegics. Paraplegia 1991; 29: 590-599.

36 Hopman MTE, Oeseburg B, Binkhorst RA. Cardiovascular responses in paraplegic subjects during arm exercise. Eur $J$ Appl Physiol 1992; 65: $73-78$.

37 Collier CR. Determination of mixed venous $\mathrm{CO}_{2}$ tension by rebreathing. J Appl Physiol 1956; 9: $25-29$.

38 Godfrey S, Wolfe E. An evaluation of rebreathing methods for measuring mixed venous $\mathrm{PCO}_{2}$ during exercise. Clin Sci 1972; 42: $345-353$.
39 Muiesan $\mathrm{G}$ et al. Comparison of $\mathrm{CO}_{2}$ rebreathing and direct Fick methods for determining cardiac output. J Appl Physiol 1968; 24: $424-429$.

40 Ferguson RJ, Faulkner JA, Julius S, Conway J. Comparison of cardiac output determined by $\mathrm{CO}_{2}$ rebreathing and dye-dilution methods. J Appl Physiol 1968; 25: 450-454.

41 Marks $\mathrm{C}$ et al. Validity and reliability of cardiac output by $\mathrm{CO}_{2}$ rebreathing. Sports Medicine 1985; 2: $432-446$

42 King ML et al. Exertional hypotension in spinal cord injury. Chest 1994; 106: $1166-1171$.

43 Sinderby et al. Electromyographical evidence for exerciseinduced diaphragm fatigue in patients with chronic cervical cord injury or prior poliomyelitis infection. Spinal Cord 1996; 34: $584-601$ 